\title{
New considerations on pathways involved in acute traumatic coagulopathy: the thrombin generation paradox
}

\author{
Cedric Gangloff ${ }^{12^{*}} \mathbb{D}$, Fanny Mingant ${ }^{3}$, Michael Theron ${ }^{1}$, Hubert Galinat ${ }^{3}$, Ollivier Grimault ${ }^{1,4}$, Yves Ozier ${ }^{1,5}$ and \\ Karine Pichavant-Rafini ${ }^{1}$
}

\begin{abstract}
Background: An acute traumatic coagulopathy (ATC) is observed in about one third of severely traumatized patients. This early, specific, and endogenous disorder is triggered by the association of trauma and hemorrhage. The early phase of this condition is characterized by the expression of a bleeding phenotype leading to hemorrhagic shock and the late phase by a prothrombotic profile leading to multiple organ failure. The physiopathology of this phenomenon is still poorly understood. Hypotheses of disseminated intravascular coagulation, activated protein C-mediated fibrinolysis, fibrinogen consumption, and platelet functional impairment were developed by previous authors and continue to be debated. The objective of this study was to observe general hemostasis disorders in case of ATC to confront these hypotheses.
\end{abstract}

Method: Four groups of 15 rats were compared: $\mathrm{C}$, control; $\mathrm{T}$, trauma; $\mathrm{H}$, hemorrhage; and $\mathrm{TH}$, trauma and hemorrhage. Blood samples were drawn at baseline and $90 \mathrm{~min}$. Thrombin generation tests, platelet aggregometry, and standard hemostasis tests were performed.

Results: Significant differences were observed between the baseline and TH groups for aPTT $(17.9 \pm 0.8 \mathrm{~s}$ vs $24.3 \pm$ $1.4 \mathrm{~s}, p<0.001$, mean \pm SEM), MAP $(79.7 \pm 1.3 \mathrm{mmHg}$ vs $43.8 \pm 1.3 \mathrm{mmHg}, p<0.001$, mean \pm SEM), and hemoglobin $(16.5 \pm 0.1 \mathrm{~g} / \mathrm{dL}$ vs $14.1 \pm 0.3 \mathrm{~g} / \mathrm{dL}, p<0.001$, mean \pm SEM), indicating the presence of an hemorrhagic shock due to ATC. Compared to all other groups, coagulation factor activities were decreased in the TH group, but endogenous thrombin potential was (paradoxically) higher than in group C (312 $\pm 17 \mathrm{nM} / \mathrm{min}$ vs. $228 \pm 23 \mathrm{nM} / \mathrm{min}$; $p=0.016$; mean \pm SEM). We also observed a subtle decrease in platelet count and function in case of ATC and retrieved an inversed linear relationship between fibrinogen concentration and aPTT (intercept, $26.53 \pm 3.16$; coefficient, $-3.40 \pm 1.26$; adjusted $R^{2}: 0.1878 ; p=0.0123$ ).

Conclusions: The clinical-biological profile that we observed, combining normal thrombin generation, fibrinogen depletion, and a hemorrhagic phenotype, reinforced the hypothesis of activated protein $C$ mediated-fibrinolysis. The key role of fibrinogen, but not of the platelets, was confirmed in this study. The paradoxical preservation of thrombin generation suggests a protective mechanism mediated by rhabdomyolysis in case of major trauma. Based on these results, we propose a new conception concerning the pathophysiology of ATC.

Keywords: Trauma, Coagulation, Shock, Thrombin, Platelet, Model

\footnotetext{
* Correspondence: cedric.gangloff@chu-rennes.f

'ORPHY Laboratory EA4324, Université de Bretagne Occidentale, Brest, France

${ }^{2}$ Department of Emergency Medicine, CHU Pontchaillou, Rennes, France

Full list of author information is available at the end of the article
}

(c) The Author(s). 2019 Open Access This article is distributed under the terms of the Creative Commons Attribution 4.0 International License (http://creativecommons.org/licenses/by/4.0/), which permits unrestricted use, distribution, and reproduction in any medium, provided you give appropriate credit to the original author(s) and the source, provide a link to the Creative Commons license, and indicate if changes were made. The Creative Commons Public Domain Dedication waiver (http://creativecommons.org/publicdomain/zero/1.0/) applies to the data made available in this article, unless otherwise stated. 


\section{Background}

One third of severe trauma patients present an acute traumatic coagulopathy (ATC) upon hospital admission. ATC is an acute, specific, and endogenous phenomenon triggered by the association of trauma and hemorrhage. Its presence is associated with higher mortality and transfusion rates [1, 2]. External factors, such as hypothermia, anti-thrombotic, and dilution, can reinforce this coagulopathy [3]. In the first hours, hemorrhage and macrocirculatory impairment are responsible for an early mortality peak. In the following days, delayed mortality due to microcirculatory defects-reflecting a prothrombotic state-is observed [4]. The physiopathology of ATC is still debated due to its complexity, but the involvement of an imbalance between pro- and anti-coagulant pathways, platelets, and endothelium are currently agreed upon [58]. However, interactions between them remain unclear. Some authors hypothesized an increased production of activated protein $\mathrm{C}(\mathrm{aPC})$ to explain the emergence of hyper-fibrinolysis in case of ATC, but this hypothesis is contradicted by studies reporting normal or increased thrombin generation after severe trauma while it should be reduced due to the inhibitory effect of aPC on FVa and FVIIIa [9-11]. This argument has been echoed by advocates of an another hypothesis: ATC would be a disseminated intravascular coagulation (DIC) associated with an early fibrinolytic phenotype explained by an endothelial release of tissue plaminogen activator (t-PA) [12-14]. These authors argued that aPC concentrations observed in case of ATC were insufficient to repress FVa and FVIIIa and lengthen prothrombin time (PT) in vitro $[15,16]$. Contradictory studies reported the absence of clinical criteria of DIC [9] or decreased thrombin generation after trauma [17]. Observation of thrombin generation on a reliable animal model of ATC, not influenced by confounding factors, would therefore make possible to confront these two hypotheses. Another unresolved concern is the role of platelet on ATC. Indeed, Jacoby et al. observed a rise in platelet-activation markers associated with hypofunctional platelets, suggesting the presence of a refractory state due to trauma $[18,19]$. In addition, a loss of platelet function was identified as a predictive factor of mortality in this context $[20,21]$. These concerns explain why thrombin generation test (TGT) and platelet aggregometry were identified as potentially useful to explore ATC [22-24]. The objective of this study was to explore the general hemostasis disorders involved in ATC's genesis to confront them with hypotheses proposed to explain its pathophysiology.

\section{Methods}

\section{Animals}

Sixty adult Sprague-Dawley rats (430-650 g, Janvier SAS, Le Genest St. Isla, France) were housed in a controlled environment (temperature $21 \pm 1{ }^{\circ} \mathrm{C}$, relative humidity $27 \pm 16 \%, 12-12 \mathrm{~h}$ light-dark cycle). All procedures were conducted following a protocol approved by the French ministry of agriculture (APAFIS\#5194-201604251313 1045) and the local university animal research ethics committee. Procedures were in line with the guide for the care and use of laboratory animals published by the US National Institute of Health [25].

\section{Preparation}

Animals were anesthetized with an intraperitoneal injection of ketamine $(100 \mathrm{mg} / \mathrm{Kg}$, Virbac, Carros, France) and xylazine $(10 \mathrm{mg} / \mathrm{kg}$, Virbac, Carros, France). They were then placed on a warming pad (Z31SY, Ascon technologic, Italy) to maintain central body temperature in a normal range $\left(37.5 \pm 0.5{ }^{\circ} \mathrm{C}\right)$. A 2 -cm cervical incision was performed, followed by a tracheostomy (2-mmdiameter polyethylene tube). An arterial catheter (Leader Flex 22G, $0.7 \times 40 \mathrm{~mm}$, Vygon, France) was inserted in the right carotid. A venous catheter was inserted in the left jugular vein (Leader Flex 22G, $0.7 \times 40 \mathrm{~mm}$, Vygon, France) followed by a continuous intravenous infusion of ketamine (1 mg/kg/h, Virbac Inc., Carros, France).

\section{Experimental procedure}

The experimental procedure is summarized in Fig. 1. Rats were allocated randomly to one of the four experimental groups ( $n=15$ per group): control $(C)$, in which neither trauma nor hemorrhage was performed; trauma $(\mathrm{T})$, in which trauma was performed but not hemorrhage; hemorrhage $(\mathrm{H})$, in which hemorrhage was performed but not trauma; trauma and hemorrhage (TH), in which trauma and hemorrhage were performed. In groups $\mathrm{H}$ and $\mathrm{TH}, 20 \%$ of total blood mass was gently collected. In groups $\mathrm{T}$ and $\mathrm{TH}$, multiple traumas were performed as follows: four closed limb fractures on the mid-height of the bone (two femurs, two humeri) at 90 angular degrees with pliers. A 4-cm median laparotomy, as well as four spleen crushings of $1 \mathrm{~cm}$ on the inferior border of the spleen, was done with surgical scissors and a needle holder.

\section{Blood samples}

All blood samples were collected through the arterial catheter. Three 15-min centrifugations were performed to obtain poor platelet plasma: one at $1000 \mathrm{~g}$ and two at $3000 \mathrm{~g}$ (centrifuge 2-16 K, Sigma, Germany). Plasma was frozen at $-80{ }^{\circ} \mathrm{C}$ until measurements.

\section{Blood analysis}

Arterial blood $\mathrm{pH}$, lactate, and potassium concentrations were measured with a point-of-care analyzer (ABL80 FLEX, Radiometer, Copenhagen, Denmark). FII, FV, FX, fibrinogen, PT, and aPTT assays were performed on an 


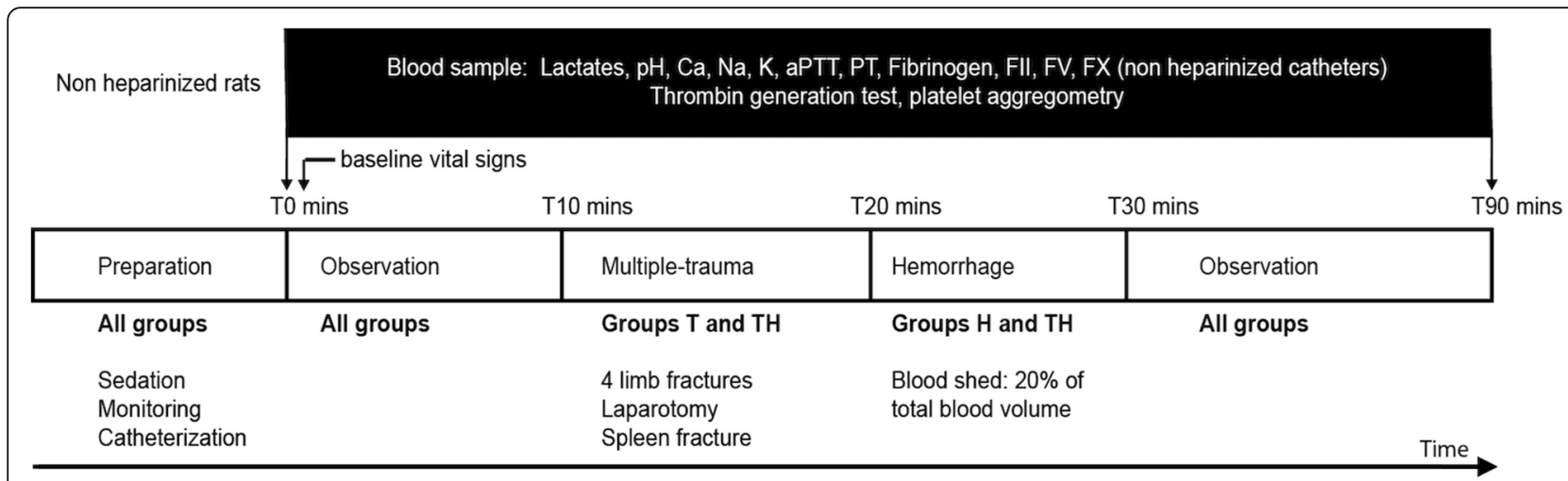

Fig. 1 Experimental protocol. Group C, without trauma without hemorrhage; T, trauma without hemorrhage; $H$, hemorrhage without trauma; TH, hemorrhage with trauma ( $n=15$ in each group)

automated analyzer (STA-R Evolution, Stago, Asnieres sur Seine, France). PT, aPTT times, and fibrinogen concentrations were measured with neoplastin $\mathrm{Cl}+10$, triniclot aPTTb, and STA liquid fib, respectively. Specific factor-depleted plasmas (Stago, Asnieres sur Seine, France) were used to determine coagulation factor activities. The thrombin generation test was performed using the Thrombinoscope CAT (Calibrated Automated Thrombogram, Maastricht, The Netherlands) assay according to the manufacturer's instructions (Diagnostica Stago, Asnières, France) $[7,8]$. Twenty microliters of plasma was incubated with $20 \mu \mathrm{L}$ PPP-ReagentTM (containing $5 \mathrm{pM}$ recombinant tissue factor and $4 \mu \mathrm{M}$ phospholipids) for $10 \mathrm{~min}$ in round-bottomed 96-well black microplates. For each sample, a calibrator (Thrombin CalibratorTM) was run in parallel in order to correct the fluorescence signal for substrate consumption and plasma color variability. Thrombin generation was initiated by the addition of $20 \mu \mathrm{L}$ of FluCa-KitTM). Fluorescence was detected by a Fluoroskan Ascent1 fluorimeter (Thermo Fischer Scientific, Waltham, MA), and the thrombin generation curves were analyzed by the thrombinoscope software (Thrombino- scope BV, Maastricht, The Netherlands). Thrombin generation curves was characterized by 5 parameters: "endogenous thrombin potential" (ETP), the area under the curve expressed in $\mathrm{nM} / \mathrm{min}$; "lagtime," the length of time required before thrombin generation starts; "peak," the highest thrombin concentration; "time to peak," the length of time until peak; and "start tail," the duration to end-point of thrombin generation. Platelet aggregometry was performed with a Multiplate analyzer (Verum Diagnostica $\mathrm{GmbH}$, Munich, Germany) in a whole blood sample, as described by the manufacturer. Three platelet agonists specific to three pathways were tested: "PAR-4 test" (70 mmol/L, PAR-4 receptor, SIGMA, St. Louis, USA); "ADP test" (10 mmol/L, ADP receptor, Roche Diagnostics $\mathrm{GmbH}$, Sandhofer Mannheim, Germany); and
"COLLtest" $(1.4 \mu \mathrm{g} / \mathrm{ml}$, collagen receptor, Roche Diagnostics GmbH, Sandhofer Mannheim, Germany). The value recorded was the area under the curve (AUC).

\section{Statistical analysis and graphics}

Statistical analyses were performed with "SPSS statistics for Macintosh" software version 21 (I.B.M. corp., Armonk, NY, 2012). Line graphs, boxplots, and histograms were generated using "Prism 7 for Mac OS X" version 7.0a (GraphPad Software, La Jolla, USA, 2016). At the time of the first sampling, the results were pooled and compared with the sampling performed at $90 \mathrm{~min}$ for each group $(\mathrm{C}, \mathrm{T}, \mathrm{H}$, and $\mathrm{TH})$. One-way ANOVA with adequate post hoc tests was used to compare means between groups. Results were expressed as the mean \pm standard error of the mean (SEM). A $p$ value $<$ 0.05 was considered statistically significant.

\section{Results}

\section{Markers of ATC}

The mean PT was statistically higher than baseline at the end of the experimentation in groups $\mathrm{C}, \mathrm{T}, \mathrm{H}$, and TH. At $90 \mathrm{~min}$, the group TH had a PT significantly longer than the $\mathrm{C}, \mathrm{T}$, and $\mathrm{H}$ groups (Fig. 2a). Similar trends were observed for aPTT (Fig. 2b).

\section{Trauma, shock, and hemorrhage markers}

Significant differences were observed between the baseline and TH group for MAP, base excess, potassium, and hemoglobin (Table 1).

\section{Thrombin generation tests}

At $90 \mathrm{~min}$, the $\mathrm{TH}$ group exhibited statistically higher ETP when compared to group C (Table 1). At the end of the experimentation, lagtime, peak, time to peak, and start tail were statistically lower than baseline in group C. Trauma by itself induced no modification when 


\section{A. Prothrombin time}

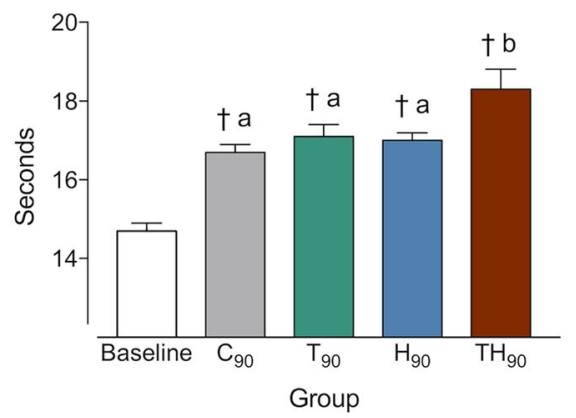

C. Factor II clotting time

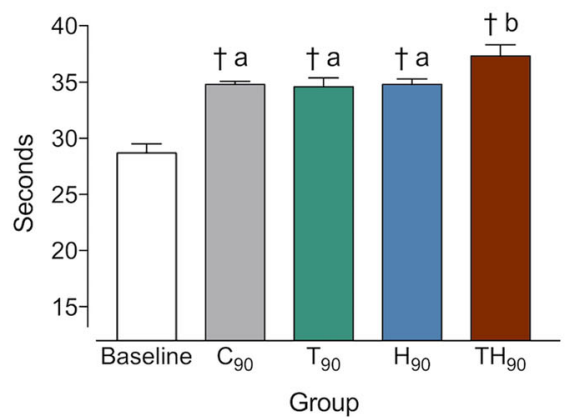

E. Factor $\mathrm{X}$ clotting time

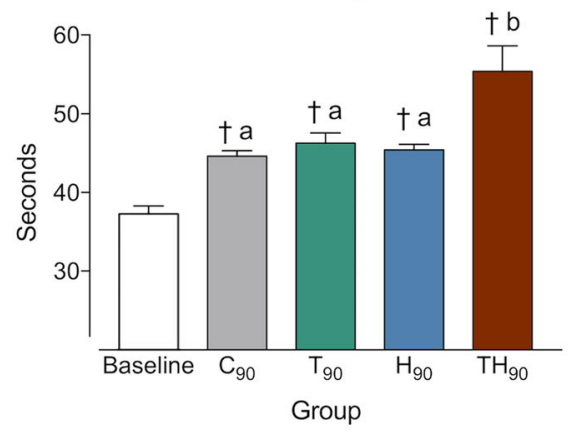

B. Activated partial thromboplastin time

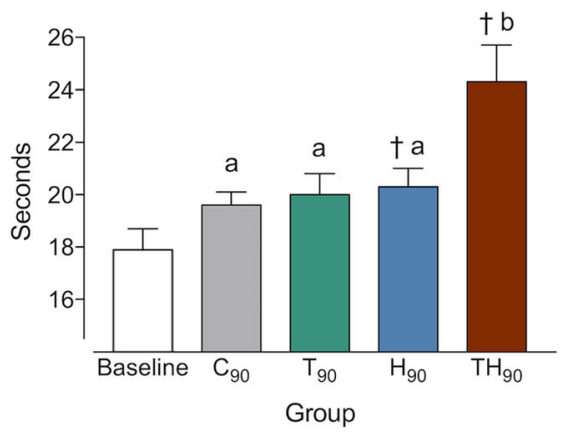

D. Factor V clotting time

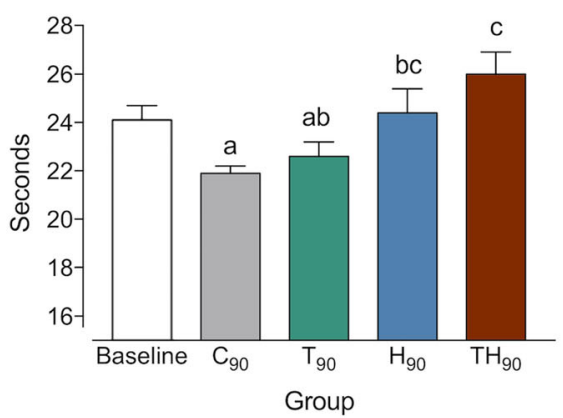

F. Fibrinogen

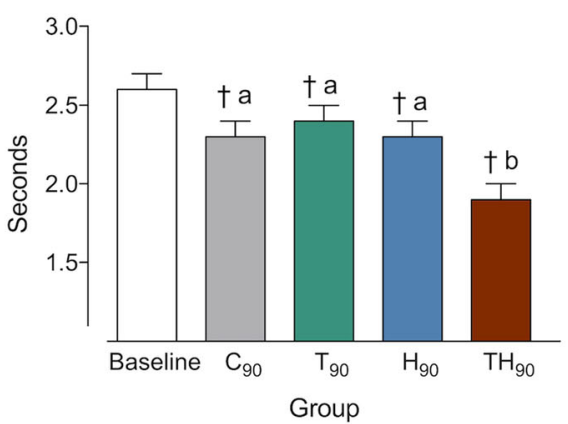

Fig. 2 Markers of ATC and coagulation factors. Baseline, pooled values from all groups at 0 min; $C_{90}$, control at 90 min; $T_{90}$, trauma at 90 min; $\mathrm{H}_{90}$, hemorrhage at $90 \mathrm{~min} ; \mathrm{TH}_{90}$, trauma and hemorrhage at $90 \mathrm{~min}$. Data are presented as mean \pm SEM. *ANOVA I significance was designated at the $p<0.05$ level of confidence. 'Significantly different from baseline. Letter differences indicate statistical differences between groups at 90 min

compared with group C. Hemorrhage alone induced an increase in lagtime, peak amplitude, and start tail.

\section{Specific coagulation assays}

In the control group, FII and FX times increased and fibrinogen concentration decreased when compared to baseline. In group $\mathrm{TH}$, all of the measured parameters were modified: FII, FV, and FX times were longer than in group $\mathrm{C}$, and the fibrinogen concentration was significantly lowered (Fig. 2c-f). A statistically significant inversed relationship between fibrinogen concentration and aPTT was observed (intercept, $26.53 \pm 3.16$; coefficient, $-3.40 \pm 1.26$; adjusted $R^{2}$ : 0.1878; $p=0.0123$ ).

\section{Platelet count and aggregometry}

Platelets slightly decreased from baseline in all groups at 90 min (Table 1). There was no effect of the different procedures at the end of the experimentation. Concerning aggregometry parameters, there was no statistical difference between groups $\mathrm{C}, \mathrm{T}, \mathrm{H}$, or $\mathrm{TH}$.

\section{Discussion}

Model relevance: this model reproduced the early phase of ATC

The mean PT and aPTT were statistically longer in group $\mathrm{TH}$ than in all other groups at the end of the experimentation. These coagulation disorders resulted in a 
Table 1 Biological assays at baseline and after procedure in each group

\begin{tabular}{|c|c|c|c|c|c|c|}
\hline Biological test & Baseline & Group $C_{90}$ & Group $T_{90}$ & Group $\mathrm{H}_{90}$ & Group $\mathrm{TH}_{90}$ & $p$ value \\
\hline \multicolumn{7}{|l|}{ Trauma, shock, and hemorrhage } \\
\hline $\mathrm{pH}$ & $7.39 \pm 0.01$ & $7.36 \pm 0.04^{a}$ & $7.41 \pm 0.01 \mathrm{ab}$ & $7.43 \pm 0.02^{b}$ & $7.45 \pm 0.05^{b \dagger}$ & $0.049^{*}$ \\
\hline Base excess (mmol/L) & $0.4 \pm 0.2$ & $-2.4 \pm 0.3^{\text {a† }}$ & $-5.4 \pm 0.8^{b \dagger}$ & $-2.6 \pm 0.5^{\text {at }}$ & $-8.03 \pm 0.9^{c \dagger}$ & $<0.001^{*}$ \\
\hline $\mathrm{PCO}_{2}$ & $43 \pm 0.86$ & $34.9 \pm 2$ & $29.6 \pm 1.8^{\dagger}$ & $30.6 \pm 1.9^{\dagger}$ & $30.8 \pm 7.9^{\dagger}$ & $<0.001^{*}$ \\
\hline Bicarbonates & $24.7 \pm 0.8$ & $19.1 \pm 0.9^{\text {a† }}$ & $18.1 \pm 0.8^{\mathrm{ab} \dagger}$ & $20.4 \pm 0.5^{\text {a† }}$ & $15.5 \pm 0.8^{\mathrm{tb}}$ & $<0.001^{*}$ \\
\hline Lactates (mmol/L) & $0.5 \pm 0.1$ & $1 \pm 0.1^{\text {at }}$ & $0.9 \pm 0.2^{\text {a† }}$ & $1.3 \pm 0.2^{a \dagger}$ & $2 \pm 0.4^{\mathrm{b} \dagger}$ & $<0.001^{*}$ \\
\hline Potassium (mmol/L) & $3.51 \pm 0.05$ & $4.55 \pm 0.22^{\text {a† }}$ & $4.68 \pm 0.13^{\text {a† }}$ & $4.39 \pm 0.13^{\text {at }}$ & $5.95 \pm 0.33^{b \dagger}$ & $<0.001^{*}$ \\
\hline Hemoglobin (g/dL) & $16.5 \pm 0.1$ & $14.8 \pm 0.2^{\mathrm{ab} \dagger}$ & $15.6 \pm 0.3^{\text {a† }}$ & $13.4 \pm 0.6^{c \dagger}$ & $14.1 \pm 0.3^{\mathrm{bct}}$ & $<0.001^{*}$ \\
\hline \multicolumn{7}{|l|}{ Thrombin generation } \\
\hline Endogenous thrombin potential (nM/min) & $269 \pm 9$ & $228 \pm 23^{a}$ & $262 \pm 15^{\mathrm{ab}}$ & $297 \pm 17^{\mathrm{ab}}$ & $312 \pm 17^{b}$ & $0.016^{*}$ \\
\hline Lagtime(min) & $2.07 \pm 0.07$ & $2.49 \pm 0.10^{\dagger}$ & $2.38 \pm 0.08^{\dagger}$ & $2.41 \pm 0.14^{\dagger}$ & $2.47 \pm 0.09^{\dagger}$ & $<0.001^{*}$ \\
\hline Peak (nmol/L) & $93.0 \pm 5.2$ & $60.5 \pm 6.7^{\mathrm{a}^{\dagger}}$ & $73.6 \pm 5.7^{\mathrm{ab} \dagger}$ & $86.9 \pm 6.8^{b}$ & $79.2 \pm 6.6^{\mathrm{ab}}$ & $0.009^{*}$ \\
\hline Time to peak (min) & $4.0 \pm 0.1$ & $4.3 \pm 0.1^{\text {at }}$ & $4.1 \pm 0.1^{\mathrm{a}}$ & $4.1 \pm 0.1^{\mathrm{a}}$ & $4.5 \pm 0.1^{\text {a† }}$ & $0.02^{*}$ \\
\hline Start tail(min) & $53.6 \pm 3.9$ & $34.3 \pm 4.2^{\text {a† }}$ & $42.2 \pm 3.2^{a}$ & $52.8 \pm 4.1^{b}$ & $40.9 \pm 4.3^{a}$ & $0.02^{*}$ \\
\hline \multicolumn{7}{|l|}{ Platelets } \\
\hline Platelets (platelets/L) & $570 \pm 8$ & $517 \pm 12^{\text {a† }}$ & $533 \pm 26^{a}$ & $493 \pm 17^{\text {a† }}$ & $525 \pm 15^{\text {a† }}$ & $<0.001^{*}$ \\
\hline PAR-4 (AUC) & $74.7 \pm 2.5$ & $69.4 \pm 4.1$ & $83.5 \pm 7.0$ & $63.3 \pm 5.7$ & $70.3 \pm 4.7$ & 0.146 \\
\hline $\mathrm{ADP}(\mathrm{A \cup C})$ & $91.0 \pm 1.8$ & $90.9 \pm 4.1$ & $100.0 \pm 5.7$ & $87.3 \pm 4.4$ & $85.3 \pm 4.3$ & 0.214 \\
\hline COLL (AUC) & $86.0 \pm 2.0$ & $77.4 \pm 2.5^{\text {a }}$ & $84.3 \pm 2.8^{a}$ & $80.5 \pm 3.6^{a}$ & $75.5 \pm 4.0^{\text {a† }}$ & $0.047^{*}$ \\
\hline
\end{tabular}

Data are presented as mean $\pm \mathrm{SEM}$. Baseline, pooled values from all groups at 0 min; $\mathrm{C}_{90}$, control at 90 min; $\mathrm{T}_{90}$, trauma at 90 min; $\mathrm{H}_{90}$, hemorrhage at 90 min; $\mathrm{TH}_{90}$, trauma and hemorrhage at 90 min. *ANOVA I significance was designated at the $p<0.05$ level of confidence. ${ }^{\dagger}$ Significant difference with baseline. Letter differences indicate statistical differences between groups. $N=15$ per group

bleeding phenotype because MAP remained lower in this group at $90 \mathrm{~min}$ (Fig. 3). Persisting hypotension was associated with an increase in lactate, reflecting an energetic imbalance in this context (Table 1). This state is called "uncompensated shock" [26]. Shock leaded to metabolic acidosis, as measured by the decrease in base excess (Table 1). Bicarbonate buffer and alveolar hyperventilation were activated in this group. Indeed, bicarbonates and

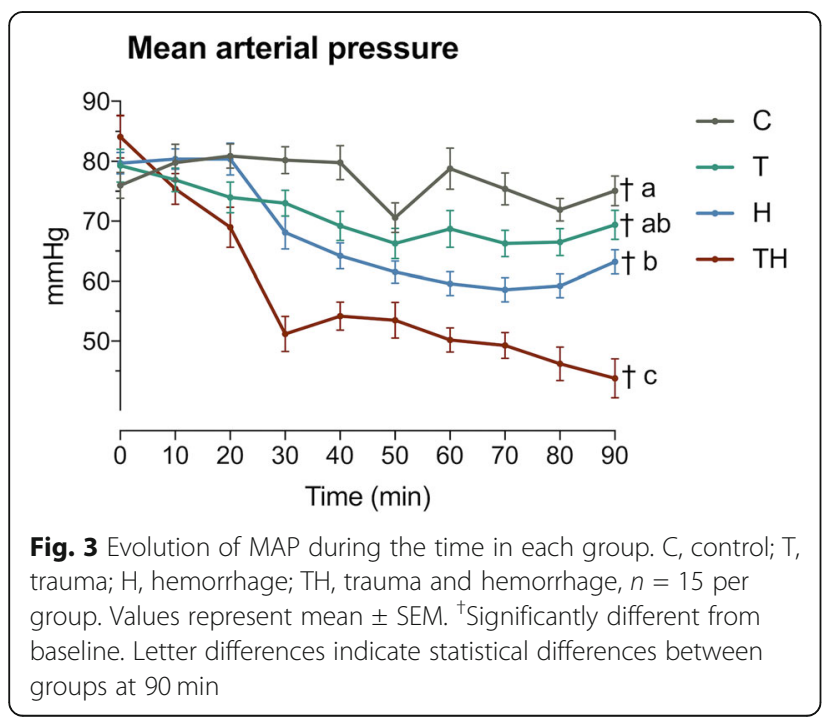

$\mathrm{pCO}_{2}$ decreased drastically, leading to a subtle rise in $\mathrm{pH}$ despite the presence of metabolic acidosis. In synthesis, the $\mathrm{TH}$ group reproduced the early phase of shock, without acidemia. Concerning potential bias, we did not use a fluid replacement that could dilute coagulation factors or antithrombotic injection to prevent clot formation, and we prevented hypothermia that could reduce clotting factor enzymatic protease activity. In consequences, the coagulation disorder observed in group $\mathrm{TH}$ fits all the characteristics defining ATC: an acute and endogenous coagulopathy specifically triggered by trauma and hemorrhage $[18,19]$.

\section{Early activation of pro- and anticoagulant pathways in case of ATC \\ The thrombin generation paradox: a statement}

ETP reflects the total amount of thrombin that a plasma sample can generate under the action of pro- and anticoagulant drivers [27-30]. In the case of coagulation factor depletion, thrombin generation tends to decrease [31]. This coagulation profile was observed in group C. Indeed, FV, FX, and ETP decreased in this group, probably due to cervical incision, tracheostomy, and catheter insertions. Paradoxically, we observed higher ETPs in group $\mathrm{TH}$ than in group $\mathrm{C}$ at the end of the experimentation despite higher FV and FX times. 
This clinical-biological profile combining a hemorrhagic phenotype, a depletion of coagulation factors, and the paradoxical preservation of thrombin generation must be confronted with the two hypotheses that have been in opposition for several years concerning ATC's pathophysiology: trauma-related DIC and aPC-mediated fibrinolysis.

In the case of DIC, a major decrease in thrombin generation [32] and platelet count [12,14] should be observed. In this experimentation, thrombin generation was preserved, and platelet count was only slightly decreased in group $\mathrm{TH}$. These results are inconsistent with the DIC hypothesis. This assumption is reinforced by the observation of a marked decrease in fibrinogen concentration, as usually observed in case of aPC-mediated fibrinolysis, and supported by several studies reporting an increase in aPC in the presence of ATC $[15,16,33]$. But the inhibition of FVa and FVIIIa by aPC should lead to a decrease in thrombin generation, suggesting the existence of a protective mechanism.

In synthesis, we observed the preservation of normal thrombin generation despite a clinical-biological profile indicating aPC-mediated fibrinolysis. These results suggest the existence of a mechanism protecting thrombin generation against aPC. We called this phenomenon the "thrombin generation paradox."

\section{Pathways involved in the thrombin generation paradox: a hypothesis}

We identified a mechanism that could explain this paradox. Indeed, the activity of the prothrombinase complex, which plays a crucial role in thrombin generation, is enhanced by two proteins whose plasma concentration increases in case of trauma-related hemorrhage: myosin and tissue factor (TF).

Major trauma leads directly to cellular damages by mechanical action on tissues [34]. Plasmatic rises in potassium, TF [35], and myosin [36, 37] due to cellular leakage are observed in this condition. This mechanism, called rhabdomyolysis or "crush syndrome," is potentialized by shock [38]. Indeed, in the case of shock, the increase in blood potassium level is correlated with the importance of tissue hypoxia [39]. Hyperkalemia is secondary to the blockage of the Na-K ATPase pump [40] and the activation of the $\mathrm{K}_{\mathrm{ATP}}$ channels triggered by cellular hypoxia $[41,42]$. This activation leads to a hyperpolarization of the cellular plasmatic membrane and blocks voltage-dependent calcium channels. Hyperpolarization leads to a decrease in myocardial contractility and vasoplegia, reinforcing shock [43, 44]. This vicious circle, leading to death, was reproduced in this experimentation: uncompensated shock and hyperkalemia were observed in group $\mathrm{TH}$. For these reasons, the rise in blood potassium observed in our study reflects the severity of tissue damages, and it can be reasonably hypothesized that it was associated with higher myosin and TF serum concentrations in group TH [45].

The role of myosin A recent study demonstrated that myosin can bind factors $\mathrm{Xa}$ and $\mathrm{Va}$, consistent with their ability to create a stable ternary complex called prothrombinase that promotes prothrombin activation [46]. Thus, a rise in myosin in group $\mathrm{TH}$ could promote thrombin generation, explaining normal ETPs despite the consumption of coagulation factors and fibrinolysis.

The role of TF As previously described, the prothrombinase complex is composed of factor $\mathrm{Va}$ and factor $\mathrm{Xa}$, and thrombin generation is directly dependent on its activity. As a consequence, a decrease in factor $\mathrm{X}$ should lead to a lowering in ETP. However, this lowering is limited in the presence of high levels of TF that promote activation of factor $X$ [47]. These patterns were retrieved in groups $C$ and TH. Indeed, a lowering in FX activity and ETP was observed in group $\mathrm{C}$, reflecting a subtle impairment in the coagulation process due to cervical incisions, tracheostomy, and catheter insertions. In contrast, a lowering of FX without a decrease in ETP was observed in group TH. In this last group, a higher level of TF due to trauma should have limited the decrease in ETP.

Clinical implications The observation of paradoxically normal ETPs in the TH group indicates the presence of procoagulant processes in case of trauma-related shock and is consistent with a recent study on humans [45]. The main advantage of this procoagulant mechanism in terms of survival could be to counterbalance the effect of coagulation factors depletion and aPC-mediated fibrinolysis. However, thrombosis is the price to pay to lower mortality [24]: a recent publication concluded that a procoagulant phenotype was a predictor of symptomatic venous thromboembolism after trauma [48]. These observations are consistent with the fact that, after several days, patients with ATC present higher mortality rates despite the restoration of normal blood pressure. Indeed, the presence of ATC is associated with multiple organ failures related to microcirculation defects [49-55].

\section{Fibrinogen plays a key role in ATC}

In our study, fibrinogen concentration was dramatically decreased in the TH group at the end of the experimentation. At the same time, the mean ETP was higher in group $\mathrm{TH}$ than in group $\mathrm{C}$. These results could be explained by the structure of fibrinogen, thrombomodulin, and thrombin. Indeed, fibrinogen and thrombomodulin have the same binding site on thrombin, the FRS site, suggesting a competitive inhibition of fibrinogen on the thrombin/thrombomodulin complex [56]. We, therefore, hypothesize that, in the case of ATC, a decrease in 


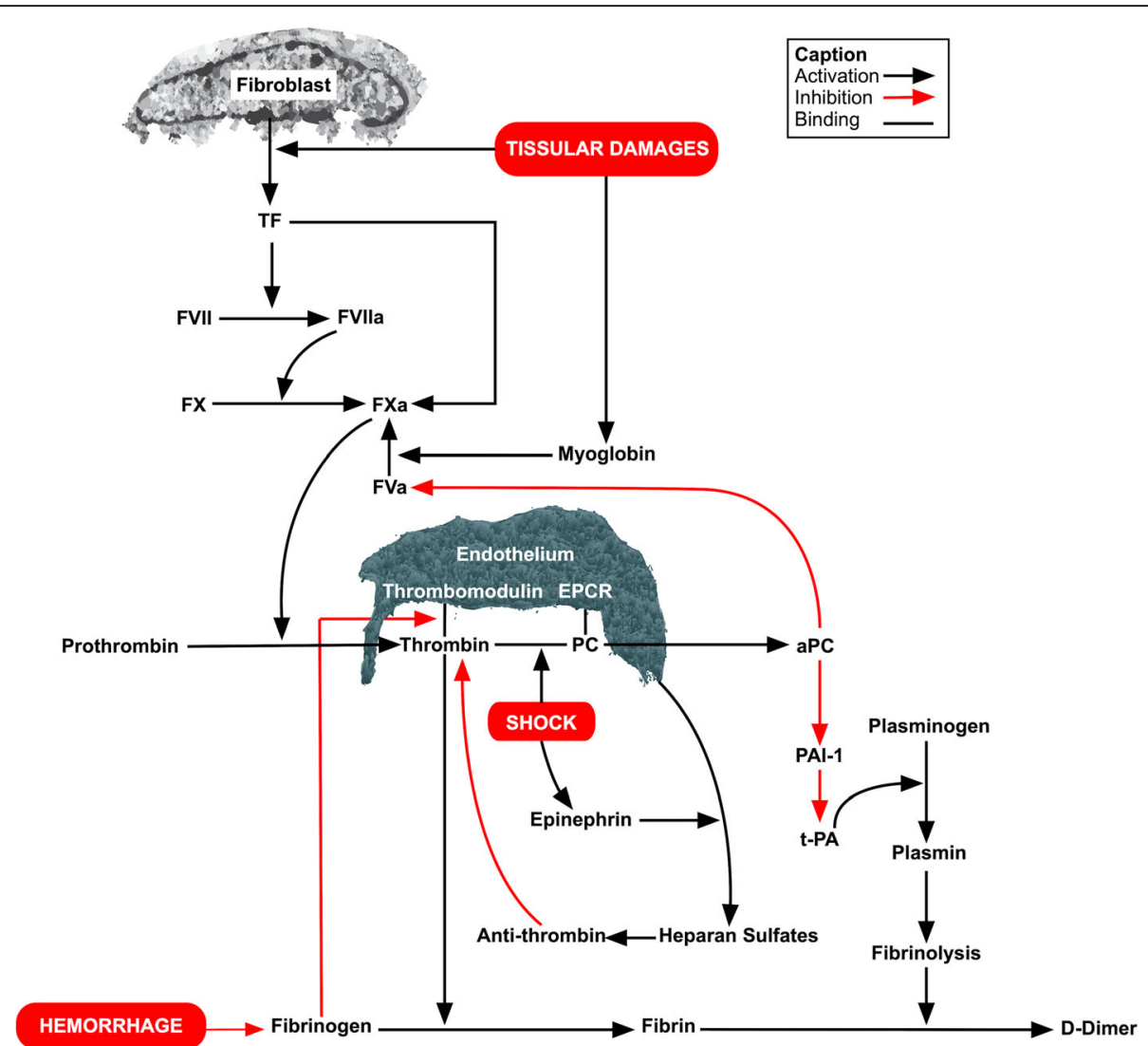

Fig. 4 New considerations on pathways involved in acute traumatic coagulopathy. Hemorrhage leads to fibrinogen depletion and decreases its competitive inhibition on the thrombin/thrombomodulin complex, enhancing protein C activation. In addition, shock induces a decrease in thrombin clearance, also increasing thrombin/thrombomodulin interactions and protein $C$ activation. The result is a hyperfibrinolysis triggered by aPC. Shock also lead to an increase in endogenous epinephrine, leading to heparan sulfate exposition on endothelial cells, activating antithrombin. The repression on coagulation mediated by antithrombin and activated protein $\mathrm{C}$ is counteracted by increases in tissue factor and myoglobin triggered by tissular damages, explaining the preservation of thrombin generation despite the expression of a hemorrhagic phenotype due to hyperfibrinolysis.

fibrinogen concentration could decrease thrombin consumption. At the same time and despite the preservation of normal thrombin concentrations, the lowering in fibrinogen concentration could decrease its competitive inhibition on the thrombin/thrombomodulin complex and activate the protein $\mathrm{C}$ pathway, reinforcing fibrinolysis. Also, we observed an inversed correlation between fibrinogen levels and aPTT, suggesting a protective role of fibrinogen against ATC. This result strengthens the hypothesis of a central role of fibrinogen in ATC's pathophysiology [57], which could be explained by a decrease in the competitive inhibition of fibrinogen on the thrombin/thrombomodulin complex, and is coherent with the hypothesis of an increase in aPC leading to fibrinolysis.

\section{ATC can occur without platelet function impairment}

Another hypothesis to explain the pathophysiology of ATC would be a loss of platelet function leading to a hemorrhagic phenotype on the early phase of trauma.
According to this hypothesis, the burst in thrombin would cause diffuse platelet activation via their PAR receptors. This excessive activation would be followed by a refractory period characterized by a loss in platelet function. In this study, we observed no increase in thrombin generation and platelet response was similar in groups $\mathrm{C}, \mathrm{T}, \mathrm{H}$, and $\mathrm{TH}$ at $90 \mathrm{~min}$. These results invalidate the hypothesis of a decrease in platelet function mediated by thrombin as a key driver in ATC's genesis. Similar results were observed in traumatized patients [22].

\section{Limitations}

This experimentation was conducted on rats, and conclusions cannot be directly transposed on humans. Previous studies enlightened quantitative differences between the two species. In particular, clot formation is more efficient on rats [58]. However, hemostasis mechanisms, playing a crucial role in survival, are highly conserved. Indeed, key components such as cells, coagulation factors, and regulation mechanisms are similar in rats and humans $[15,57$, 
59-64]. It is therefore reasonable to assume that hemostasis disorders are also very close $[1,61,65,66]$. Moreover, in this experimentation, low volumes of blood were sampled in order to avoid mimicking excessive bleedings, which would have biased the experiment. The small volumes of blood samples collected were insufficient to confirm all hypothesis developed in this experimentation, especially concerning fibrinolysis. All these hypothesis needs to be validated in clinical studies.

\section{Conclusion}

ATC resulted in a specific clinical-biological profile combining a hemorrhagic phenotype, the depletion of coagulation factors, and the preservation of thrombin generation. These results are consistent with excessive fibrinolysis mediated by aPC. The crucial role of fibrinogen in ATC was confirmed in this experimentation and could be explained by a decrease of its competitive inhibition on the thrombin/thrombomodulin complex, reinforcing fibrinolysis. The paradoxically preserved thrombin generation in this setting suggests a protective mechanism mediated by myoglobin and TF. We also observed that ATC could occur without significant impairment in platelet function. As a consequence, this experimentation led to a better understanding of ATC's pathophysiology, which appears to be partially counterbalanced by survival-related mechanisms at the cost of an increase in thrombotic events. We propose a new conception concerning ATC's pathophysiology based on these results (Fig. 4).

\section{Abbreviations \\ aPC: Activated protein C; aPTT: Activated partial thromboplastin time; ATC: Acute traumatic coagulopathy; DIC: Disseminated intravascular coagulation; ETP: Endogenous thrombin potential; MAP: Mean arterial pressure; PC: Protein C; PT: Prothrombin time; t-PA: Tissue plasminogen activator; TF: Tissue factor; TGT: Thrombin generation test}

\section{Acknowledgements}

Not applicable.

\section{Authors' contributions}

$C G, K P$, and MT designed the experiment. CG performed the experiments. CG and MT performed the statistical analysis. HG and FM performed TGT. CG wrote the manuscript. All authors read and approved the final manuscript.

\section{Funding}

Funding information is not applicable.

\section{Availability of data and materials}

The dataset used and analyzed during the current study is available from the corresponding author on reasonable request.

\section{Ethics approval and consent to participate}

All procedures were conducted following a protocol approved by the French Ministry of Agriculture (APAFIS\#5194-2016042513131045) and the local university Animal Research Ethics Committee. Procedures were in accordance with the guide for the care and use of laboratory animals published by the US National Institute of Health.

\section{Consent for publication}

Not applicable

\section{Competing interests}

The authors declare that they have no competing interests.

\section{Author details}

1ORPHY Laboratory EA4324, Université de Bretagne Occidentale, Brest, France. ${ }^{2}$ Department of Emergency Medicine, CHU Pontchaillou, Rennes, France. ${ }^{3}$ Department of Biology and Hemostasis, CHRU Cavale Blanche, Brest, France. ${ }^{4}$ Department of Emergency Medicine, Hôpital de la Cavale Blanche, Brest, France. ${ }^{5}$ Department of Anaesthesiology, Hôpital de la Cavale Blanche, Brest, France.

Received: 26 September 2019 Accepted: 11 November 2019

Published online: 12 December 2019

\section{References}

1. Frith D, Goslings JC, Gaarder C, et al. Definition and drivers of acute traumatic coagulopathy: clinical and experimental investigations. J Thromb Haemost. 2010;8:1919-25.

2. Peltan ID, Vande Vusse LK, Maier RV, et al. An INR-based definition of acute traumatic coagulopathy is associated with mortality, venous thromboembolism, and multiple organ failure after injury. Crit Care Med. 2015:43:1429-38.

3. Dutton RP, Stansbury LG, Leone S, et al. Trauma mortality in mature trauma systems: are we doing better? An analysis of trauma mortality patterns, 1997-2008: The Journal of Trauma: Injury. Infection, and Critical Care. 2010;69:620-6.

4. Oshiro A, Yanagida Y, Gando S, et al. Hemostasis during the early stages of trauma: comparison with disseminated intravascular coagulation. Crit Care. 2014;18:R61.

5. Dobson GP, Letson HL, Sharma R, et al. Mechanisms of early traumainduced coagulopathy: the clot thickens or not? J Trauma Acute Care Surg. 2015;79:301-9.

6. Hess JR, Brohi K, Dutton RP, et al. The coagulopathy of trauma: a review of mechanisms. J Trauma. 2008;65:748-54.

7. Cohen MJ, Kutcher M, Redick B, et al. Clinical and mechanistic drivers of acute traumatic coagulopathy. J Trauma Acute Care Surg. 2013;75:S40-7.

8. Xiao W, Mindrinos MN, Seok J, et al. A genomic storm in critically injured humans. J Exp Med. 2011;208:2581-90.

9. Johansson Pl, Sørensen A, Perner A, et al. Disseminated intravascular coagulation or acute coagulopathy of trauma shock early after trauma? An observational study. Critical Care. 2011;15:R272.

10. Davenport RA, Guerreiro M, Frith D, et al. Activated protein C drives the hyperfibrinolysis of acute traumatic coagulopathy. Anesthesiology. 2017;126:115-27.

11. Yanagida $Y$, Gando S, Sawamura A, et al. Normal prothrombinase activity, increased systemic thrombin activity, and lower antithrombin levels in patients with disseminated intravascular coagulation at an early phase of trauma: comparison with acute coagulopathy of trauma-shock. Surgery. 2013;154:48-57.

12. Gando S, Levi M, Toh C-H. Disseminated intravascular coagulation. Nature Reviews Disease Primers. 2016;2:16037.

13. Gando S, Mayumi T, Ukai T: Activated protein C plays no major roles in the inhibition of coagulation or increased fibrinolysis in acute coagulopathy of trauma-shock: a systematic review [Internet]. Thrombosis Journal 2018; 16[cited 2018 Oct 26] Available from: https:// doi.org/10.1186/s12959-018-0167-3

14. Gando S, Otomo Y. Local hemostasis, immunothrombosis, and systemic disseminated intravascular coagulation in trauma and traumatic shock. Critical Care. 2015;19:72.

15. Campbell JE, Meledeo MA, Cap AP. Comparative response of platelet $\mathrm{fV}$ and plasma $\mathrm{A}$ to activated protein $\mathrm{C}$ and relevance to a model of acute traumatic coagulopathy. PLOS ONE. 2014;9:e99181.

16. Howard BM, Kornblith LZ, Cheung CK, et al. Inducing acute traumatic coagulopathy in vitro: the effects of activated protein $C$ on healthy human whole blood. PLoS One. 2016;11:e0150930.

17. Harr JN, Moore EE, Wohlauer MV, et al.: The acute coagulopathy of trauma is due to impaired initial thrombin generation but not clot formation or clot strength [Internet]. Journal of Surgical Research 2011; [cited 2018 Oct 12] Available from: http://linkinghub.elsevier.com/ retrieve/pii/S0022480411002861 
18. Jacoby RC, Owings JT, Holmes J, et al. Platelet activation and function after trauma: The Journal of Trauma: Injury. Infection, and Critical Care. 2001;51:639-47.

19. Wohlauer MV, Moore EE, Thomas S, et al. Early platelet dysfunction: an unrecognized role in the acute coagulopathy of trauma. Journal of the American College of Surgeons. 2012;214:739-46.

20. Kutcher ME, Redick BJ, McCreery RC, et al.: Characterization of platelet dysfunction after trauma: Journal of Trauma and Acute Care Surgery 2012; 73:13-19

21. Furay EJ, Daley MJ, Teixeira PG, et al.: Goal directed platelet transfusions correct platelet dysfunction and may improve survival in patients with severe traumatic brain injury: Journal of Trauma and Acute Care Surgery 2018; 1

22. George MJ, Burchfield J, MacFarlane B, et al.: Multiplate and TEG platelet mapping in a population of severely injured trauma patients: multiplate and TEG platelet mapping in trauma [Internet]. Transfusion Medicine 2017; [cited 2017 Oct 5] Available from: https://doi.org/10.1111/tme.12473

23. Ninivaggi M, Apitz-Castro R, Dargaud Y, et al. Whole-blood thrombin generation monitored with a calibrated automated thrombogram-based assay. Clinical Chemistry. 2012;58:1252-9.

24. Al Dieri R, de Laat B, Hemker HC. Thrombin generation: what have we learned? Blood Reviews. 2012;26:197-203.

25. Committee for the Update of the Guide for the Care and Use of Laboratory Animals: Guide for the Care and Use of Laboratory Animals [Internet]. National Research Council of the National Academies 2011; Available from: https:/grants.nih.gov/grants/olaw/guide-for-the-care-and-use-of-laboratoryanimals.pdf

26. Rossaint R, Bouillon B, Cerny V, et al. The European guideline on management of major bleeding and coagulopathy following trauma: fourth edition. Crit Care. 2016;20:100

27. Lancé MD, Ninivaggi $M$, Schols SEM, et al. Perioperative dilutional coagulopathy treated with fresh frozen plasma and fibrinogen concentrate: a prospective randomized intervention trial: Dilutional coagulopathy treated with FFP and fibrinogen. Vox Sanguinis. 2012;103:25-34

28. Tripodi A. Thrombin generation assay and its application in the clinical laboratory. Clinical Chemistry. 2016;62:699-707.

29. Lancé MD. A general review of major global coagulation assays: thrombelastography, thrombin generation test and clot waveform analysis. Thrombosis journal. 2015;13:1.

30. Hemker $\mathrm{H}$. Thrombin generation, a function test of the haemostaticthrombotic system; 2008.

31. Martini WZ, Cortez DS, Dubick MA, et al.: Different recovery profiles of coagulation factors, thrombin generation, and coagulation function afte hemorrhagic shock in pigs: Journal of Trauma and Acute Care Surgery 2012; 73:640-647

32. Kawasugi K: Thrombin generation test in patients with DIC]. Rinsho Byori 2011; Suppl 147:62-64

33. Brohi K, Cohen MJ, Ganter MT, et al. Acute traumatic coagulopathy: initiated by hypoperfusion: modulated through the protein C pathway? Annals of Surgery. 2007;245:812-8.

34. Rocksén D, Gryth D, Druid H, et al. Pathophysiological effects and changes in potassium, ionised calcium, glucose and haemoglobin early after severe blunt chest trauma. Injury. 2012:43:632-7.

35. Howard BM, Miyazawa BY, Dong W, et al.: The tissue factor pathway mediates both activation of coagulation and coagulopathy after injury: Journal of Trauma and Acute Care Surgery 2015; 79:1009-1014

36. Löfberg $M$, Tähtelä $R$, Härkönen $M$, et al. Myosin heavy-chain fragments and cardiac troponins in the serum in rhabdomyolysis: diagnostic specificity of new biochemical markers. Archives of neurology. 1995;52:1210-4.

37. Guerrero M, Guiu-Comadevall M, Cadefau JA, et al. Fast and slow myosins as markers of muscle injury. British Journal of Sports Medicine. 2008:42:581-4

38. Huerta-Alardín AL, Varon J, Marik PE. Bench-to-bedside review: rhabdomyolysis-an overview for clinicians. Critical care. 2004;9:158

39. Rocha Filho JA, Nani RS, LAC DA, et al. Potassium in hemorrhagic shock: a potential marker of tissue hypoxia: The Journal of Trauma: Injury. Infection, and Critical Care. 2010;68:1335-41.

40. Terkildsen JR, Crampin EJ, Smith NP. The balance between inactivation and activation of the $\mathrm{Na}+-\mathrm{K}+$ pump underlies the triphasic accumulation of extracellular K+ during myocardial ischemia. AJP: Heart and Circulatory Physiology. 2007;293:H3036-45.
41. Ashcroft SJ, Ashcroft FM. Properties and functions of ATP-sensitive Kchannels. Cellular signalling. 1990;2:197-214.

42. Buckley J, Singer M, Clapp L. Role of KATP channels in sepsis. Cardiovascular Research. 2006;72:220-30

43. Lange M, Morelli A, Westphal M. Inhibition of potassium channels in critical illness. Current Opinion in Anesthesiology. 2008:21:105-10.

44. Evgenov OV, Pacher P, Williams W, et al.: Parenteral administration of glipizide sodium salt, an inhibitor of adenosine triphosphate-sensitive potassium channels, prolongs short-term survival after severe controlled hemorrhage in rats*: Critical Care Medicine 2003; 31:2429-2436

45. Matijevic N, Wang Y-WW, Wade CE, et al. Cellular microparticle and thrombogram phenotypes in the Prospective Observational Multicenter Major Trauma Transfusion (PROMMTT) Study: Correlation with coagulopathy. Thrombosis Research. 2014;134:652-8.

46. Deguchi $H$, Sinha RK, Marchese $P$, et al. Prothrombotic skeletal muscle myosin directly enhances prothrombin activation by binding factors $\mathrm{Xa}$ and va. Blood. 2016:128:1870-8.

47. Duchemin J: influence of coagulation factors and tissue factor concentration on the thrombin generation test in plasma. Thromb Heamost 2008;

48. Park MS, Spears GM, Bailey KR, et al. Thrombin generation profiles as predictors of symptomatic venous thromboembolism after trauma: a prospective cohort study. Journal of Trauma and Acute Care Surgery. 2017. 83:381-7.

49. Morris RS, Schaffer BS, Lundy JB, et al. Immunopathological response to severe injury: platelet activation and the Th-17 immune response. Blood Coagulation \& Fibrinolysis. 2017;1.

50. Seshadri A, Brat GA, Yorkgitis BK, et al. Phenotyping the immune response to trauma: a multiparametric systems immunology approach*. Critical Care Medicine. 2017:45:1523-30.

51. Lenz A, Franklin GA, Cheadle WG. Systemic inflammation after trauma. Injury. 2007:38:1336-45

52. Nast-Kolb D, Aufmkolk M, Rucholtz S, et al. Multiple organ failure still a major cause of morbidity but not mortality in blunt multiple trauma. Journal of Trauma and Acute Care Surgery. 2001;51:835-42.

53. Gando S, Sawamura A, Hayakawa M. Trauma, shock, and disseminated intravascular coagulation: lessons from the classical literature. Annals of Surgery. 2011;254:10-9.

54. Owen HC, Torrance HDT, Jones TF, et al.: Epigenetic regulatory pathways involving microRNAs may modulate the host immune response following major trauma: Journal of Trauma and Acute Care Surgery 2015; 79:766-772

55. Osborn TM, Tracy JK, Dunne JR, et al.: Epidemiology of sepsis in patients with traumatic injury: Critical Care Medicine 2004; 32:2234-2240

56. De Cristofaro R, De Candia E. Thrombin domains: structure, function and interaction with platelet receptors. Journal of Thrombosis and Thrombolysis. 2003:15:151-63.

57. David J-S, Levrat A, Bouzat P: Fibrinogen measurement and viscoelastic technique are necessary to define acute traumatic coagulopathy: Critical Care Medicine 2016; 44:e106

58. Dibiasi C, Plewka J, Ploszczanski L, et al. Viscoelasticity and structure of blood clots generated in-vitro by rheometry: a comparison between human, horse, rat, and camel. CH. 2018;69:515-31.

59. Donahue DL, Beck J, Fritz B, et al. Early platelet dysfunction in a rodent model of blunt traumatic brain injury reflects the acute traumatic coagulopathy found in humans. Journal of Neurotrauma. 2014;31:404-10.

60. Girish A, Hickman DA, Banerjee A, et al. Trauma-targeted delivery of tranexamic acid improves hemostasis and survival in rat liver hemorrhage model. J Thromb Haemost. 2019;17:1632-44.

61. Hagemo JS, Jorgensen JJ, Ostrowski SR, et al. Changes in fibrinogen availability and utilization in an animal model of traumatic coagulopathy. Scand J Trauma Resusc Emerg Med. 2013;21:56.

62. Iwamoto S, Takasu A, Sakamoto T. Therapeutic mild hypothermia: effects on coagulopathy and survival in a rat hemorrhagic shock model. J Trauma. 2010;68:669-75.

63. Lupu $\mathrm{C}$, Herlea $\mathrm{O}$, Tang $\mathrm{H}$, et al. Plasmin-dependent proteolysis of tissue factor pathway inhibitor in a mouse model of endotoxemia: Plasmin proteolysis of TFPI in endotoxemia. Journal of Thrombosis and Haemostasis. 2013;11:142-8

64. van Zyl N, Reade MC, Fraser JF. Experimental animal models of traumatic coagulopathy: a systematic review. Shock. 2015. 
65. Frith $\mathrm{D}$, Cohen MJ, Brohi K. Animal models of trauma-induced coagulopathy. Thromb Res. 2012;129:551-6.

66. Boudreau RM, Johnson M, Veile R, et al. Impact of tranexamic acid on coagulation and inflammation in murine models of traumatic brain injury and hemorrhage. Journal of Surgical Research. 2017;215:47-54.

\section{Publisher's Note}

Springer Nature remains neutral with regard to jurisdictional claims in published maps and institutional affiliations.

Ready to submit your research? Choose BMC and benefit from:

- fast, convenient online submission

- thorough peer review by experienced researchers in your field

- rapid publication on acceptance

- support for research data, including large and complex data types

- gold Open Access which fosters wider collaboration and increased citations

- maximum visibility for your research: over $100 \mathrm{M}$ website views per year

At BMC, research is always in progress. 